\title{
Placement of vena cava filter via percutaneous puncture of the great saphenous vein
}

\author{
YIQI JIN, DAYONG ZHOU, LEI CHEN, XIANCHEN HUANG, GUOXIONG XU, JIAN HUANG and LIMING SHEN \\ Department of Vascular Surgery, Affiliated Suzhou Hospital of Nanjing Medical University, \\ Suzhou Municipal Hospital, Suzhou, Jiangsu 215002, P.R. China
}

Received December 23, 2012; Accepted March 5, 2013

DOI: 10.3892/etm.2013.1157

\begin{abstract}
The aim of this study was to investigate the feasibility and safety of vena cava filter (VCF) placement via percutaneous puncture of the great saphenous vein (GSV) in the prevention of pulmonary embolisms. Using ultrasound positioning, VCF placement via percutaneous puncture of the GSV was performed on 12 patients with deep vein thrombosis (DVT) in the lower extremities. Transcatheter thrombolysis was conducted simultaneously. The postoperative filter position, puncture wound recovery and fluency of the GSV were observed. All filters were successfully released, with accurate positioning. No hematoma was observed at the puncture point during the perioperative period. In certain patients, local petechiae appeared around the puncture point during the thrombolysis period, which did not require special treatment. Re-examination using ultrasound revealed unobstructed blood flow in the GSV. VCF placement via percutaneous puncture of the GSV is a new filter placement method. The feasibility and safety of this method for the prevention of pulmonary embolisms has been demonstrated in a small number of sample cases.
\end{abstract}

\section{Introduction}

The incidence of pulmonary embolism is increasing, and deep vein thrombosis (DVT) in the lower extremities is one of the main causes. It is reported that one-third of patients with an acute phase of DVT may suffer from acute pulmonary embolisms $(1,2)$. Vena cava filter (VCF) placement is an effective measure for preventing pulmonary embolisms in DVT patients. It has the advantage of being a simple procedure, with minimal trauma and few complications, and has been widely applied clinically (3-6). As the outer sheaths of commercially available filters are becoming increasingly thinner, the traditional

Correspondence to: Dr Liming Shen, Vascular Surgery, Affiliated Suzhou Hospital of Nanjing Medical University, Suzhou Municipal Hospital, 26 Daoqian Street, Suzhou, Jiangsu 215002, P.R. China E-mail: limingshencn@126.com

Key words: percutaneous puncture, great saphenous vein, vena cava filter
VCF placement method has changed from the percutaneous incision of a deep vein to Seldinger's method $(7,8)$, dominated by the percutaneous puncture of a deep vein. Currently, the placement pathways for VCFs are mainly the femoral and jugular veins (9), and the pathways of the subclavian, brachial and external jugular veins have also been reported $(10,11)$. However, since a risk of complications arising from VCF placement via puncture of a deep vein remains, it is important to investigate safe and feasible puncture pathways for clinical use. The great saphenous vein (GSV), as a superficial vein, is not a traditional pathway for intracavitary therapy in lower extremity veins, but the puncture and incision via the superficial venous pathway has been reported $(12,13)$. In the current study, using ultrasound positioning, the placement of a VCF via the percutaneous puncture of the GSV was performed on DVT patients, and the feasibility and safety of this method were investigated.

\section{Materials and methods}

General data. A total of 12 patients with DVT $(5$ males and 7 females) were enrolled in this study at the Affiliated Suzhou Hospital of Nanjing Medical University. The patients were aged between 48 and 87 years, with an average age of 51.5 years (Table I). The disease onset time was $<1$ week. All patients were diagnosed with unilateral DVT (left lateral, 9 cases; right lateral, 3 cases) using color Doppler ultrasound, venography and plasma D-dimer determination. According to the results of the venography, there were 4 central type, 4 peripheral type and 4 mixed type cases of DVT. VCFs were provided by Johnson \& Johnson Co. (New Brunswick, NJ, USA). Trapease ${ }^{\circledR}$ permanent filters were used to treat 4 patients, while the other 8 patients were treated with Optease ${ }^{\circledR}$ temporary filters. THe present study was approved by the Ethics Committee of Affiliated Suzhou Hospital of Nanjing Medical University (Suzhou, China). Informed consent was obtained from the patient.

Preoperative preparation. A preoperative routine blood test, blood coagulation test and other examinations were conducted on all patients. The inclusion criteria for VCF placement were as follows: definite pulmonary infarction symptoms or tendency, contraindication of anticoagulation, consideration of transcatheter thrombolysis, poor anticoagulation or re-thrombosis. 
Table I. Clinical and puncture characteristics.

\begin{tabular}{lc}
\hline Total (n) & 12 \\
Male & 5 \\
Female & 7 \\
Age, mean (range), years & $51.5(48-87)$ \\
DVT (n) & 4 \\
Central & 4 \\
Peripheral & 4 \\
Mixed & \\
GSV puncture (n) & 9 \\
Left & 3 \\
Right & \\
\hline
\end{tabular}

DVT, deep venous thrombus; GSV, great saphenous vein.

Surgical methods. VCF placements via puncture of the unaffected lateral and affected lateral GSV were performed on 10 and 2 (central type) patients, respectively. The selected puncture point was located at the upper-middle segment of the inner thigh. After disinfection and local anesthesia, the thigh was ligatured using a tourniquet to temporarily block venous return and vein dilatation. Using color Doppler ultrasound positioning, puncture of the GSV was performed, and the gliding guide wire was placed, from the saphenous vein valve to the femoral vein and then on to the vena cava. The remaining surgical steps were the same as with a traditional filter placement method. The venography was conducted and once the outlet positions of bilateral renal veins were determined, the filter was released.

After releasing the filter, transcatheter thrombolysis in a deep vein by puncturing the jugular vein was undertaken in the majority of patients $(14,15)$. For patients with thrombosis in the entirety of their lower extremities, transcatheter thrombolysis was conducted in the affected lateral femoral artery. For two patients with central type DVT, after puncturing the GSV, the catheter was placed directly into the thrombus for thrombolysis. The puncture wound of the GSV was treated with pressure bandaging.

Postoperative treatment. After lying in a horizontal position for $6 \mathrm{~h}$ postoperatively, the patients were able to perform out-of-bed activities, with the exception of 2 cases where there was catheterization in the GSV. For patients undergoing thrombolytic and anticoagulant therapies, the coagulation change was monitored, and oozing ecchymosis at the puncture point and at the catheterization site was observed every day. The thrombolytic situation was monitored by venography to enable adjustment of the catheter position. The catheter was extubated 2 weeks after thrombolysis; furthermore, the temporary filters may be retrieved after thrombolysis.

\section{Results}

All filters were successfully released, using accurate ultrasound positioning. In 6 out of 8 patients with temporary filter placement, filters were successfully retrieved within 3 weeks
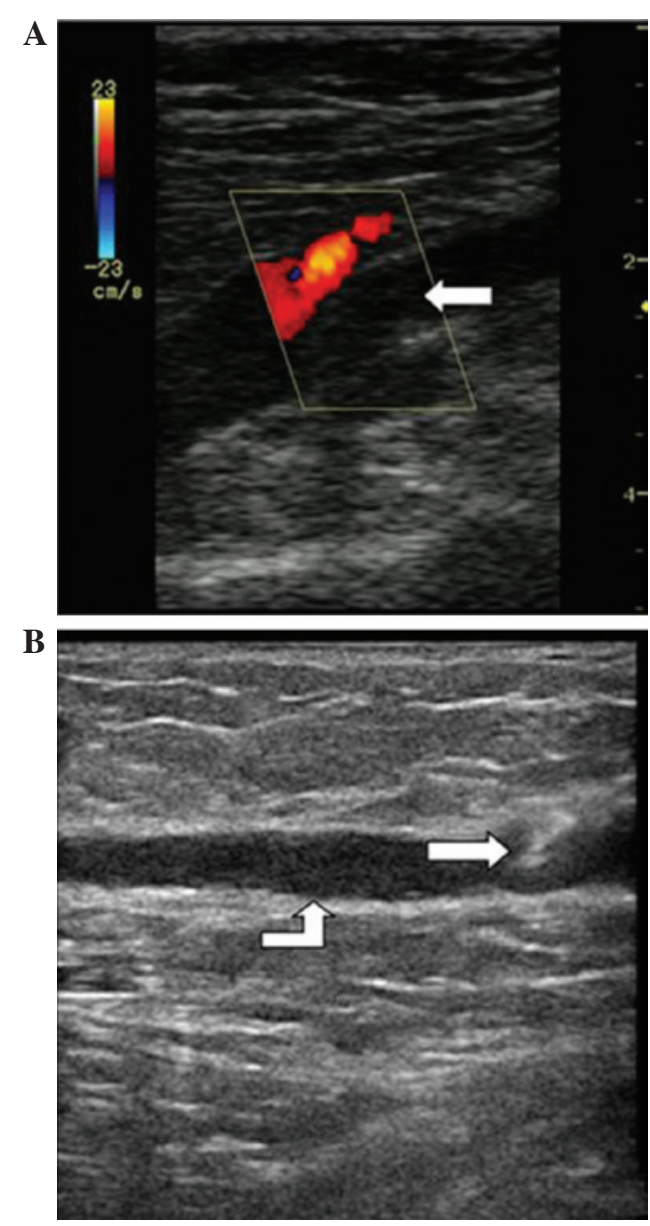

Figure 1. Color Doppler ultrasound of VCF placement. (A) deep vein thrombus (arrow); (B) puncture needle (straight arrow) and GSV (bent arrow). VCF, vena cava filter; GSV, great saphenous vein.

of surgery. A further two patients did not undergo retrieval due to economic reasons. The ultrasound-guided puncture was successfully conducted on all patients (Fig. 1). Throughout the perioperative period, there was no marked hematoma at the puncture point. For some patients, local petechiae appeared around the puncture point during the thrombolysis period, which did not require treatment. For all patients, re-examination with a color Doppler ultrasound revealed unobstructed blood flow in the GSV, with no back flow or thrombosis. Within 1 year of follow-up there had been no instances of pulmonary embolism.

\section{Discussion}

At present, VCF placement via puncture of a deep vein (Seldinger's method) is widely used in a clinical environment. This method has many advantages, including less trauma and fewer complications, and it is a simple surgery. However, puncture of a deep vein, particularly the femoral vein, has the following disadvantages: i) a hematoma is easily formed in anticoagulant and thrombolytic conditions, and it is difficult to detect and treat early due to its deep position. ii) There is a risk of local thrombosis at the puncture and catheterization site. iii) The femoral venous valve may be damaged. iv) Puncture is seldom successful for obese patients. v) The 
arteries may be mistakenly punctured, particularly for patients in whom the femoral vein is located on the dorsal side of the femoral artery. Additionally, the risk of hematoma and pseudoaneurysm formation will be aggravated during subsequent anticoagulant and thrombolytic therapy. vi) The puncture point is near the perineum, leading to problems with postoperative care $(16,17)$.

However, puncture of the GSV may avoid the risks listed above. Most regions of the GSV are located at the superficial fascia layer. It is possible to detect bleeding or hematoma early and easily, and compression hemostasis is easily conducted. Due to shielding by the saphenofemoral valve, the inner wall and valve of the GSV to not readily become detached and enter the deep vein, even if the injury has induced secondary thrombosis. Therefore, the probability of deep vein valve injury is very low. The anatomical location of the GSV is superficial, with no accompanying artery. The puncture site is relatively flexible when using ultrasound positioning, and the iliac region may be avoided.

GSV puncturing has been performed by a number of physicians. For example, transcatheter thrombolysis and stent placement through the saphenous vein pathway have been conducted by interventional physicians with good results. Additionally, filter placement via GSV incision has also been performed, and the aforementioned advantages have been confirmed (18-24). Anatomical data indicate that the full diameter of a normal GSV is $>2 \mathrm{~mm}$ and that in the thigh it is 3.2-4.0 $\mathrm{mm}$ (25). However, temporarily blocking superficial venous backflow may cause vein dilatation, enabling the GSV to accommodate a 6-7 F filter. Therefore, VCF placement via puncture of the GSV has a theoretical and practical basis, and the feasibility is demonstrated in the current study.

In this study, as the affected lateral GSV in the DVT patient is one of the important compensatory lateral branches, the puncture is conducted on an unaffected lateral GSV. This avoids injury to the affected lateral GSV and the effect on compensatory venous backflow. During follow-up, GSV injuries caused by the puncture, including thrombus formation, valve damage and blood reflux, have not been observed. Filter placement and transcatheter thrombolysis via puncture of the GSV were performed on two patients with central type DVT. The entire procedure was completed with only one puncture wound on the superficial vein, and it was minimally invasive with a satisfactory result. However, this method still has clinical disadvantages, as the filter sheath may cause shedding of the thrombus, leading to acute pulmonary embolism.

The VCF used in this study, with a $6 \mathrm{~F}$ diameter, is much thinner than other commercially available products. Furthermore, this filter has advantages such as a simple releasing procedure, convenient positioning and a higher success rate of retrieval (retrievable filter) (26-30). At present, retrievable filters are more likely to be used in a clinical setting, for the following reasons: firstly, the indications for filter placement are controversial, and previously reported results of long-term efficacy and complications differ (31-34); and secondly, in younger patients with DVT, a permanent filter would not be suitable.

In the current study, VCF placement via puncture of the GSV has not provided optimal results. The injury risk of GSV puncture remains and, most notably, commercially available filters have not provided the ideal minimally invasive result. In our hospital, GSV radiofrequency laser closure surgery has been conducted on $>500$ patients and as such we have accumulated a large amount of experience. Puncture of the GSV on the upper medial malleolus has been conducted successfully in the majority of patients, with the placement of a 6-8 F sheath. The advantages of puncture at this position are as follows: i) The surgery is simple. For the majority of patients ultrasound positioning is not required, and a trocar may been placed under direct vision. It is possible to complete the puncture using a small guide wire (diameter, 0.018 inch). ii) As the GSV is located at the surface of the medial malleolus, it is easier to conduct the compression hemostasis, and wound oozing is easily observed. However, due to the shorter length of the filter, it is not possible to further attempt these measures at present.

In conclusion, $\mathrm{VCF}$ placement via percutaneous puncture of the GSV is a new filter placement method. The feasibility and safety of this method for the prevention of pulmonary embolism has been demonstrated in a small set of sample cases.

\section{References}

1. Imberti D, Ageno W, Manfredini R, et al: Interventional treatment of venous thromboembolism: a review. Thromb Res 129: 418-425, 2012

2. White RH: The epidemiology of venous thromboembolism. Circulation 107: I4-I8, 2003.

3. Kearon C, Kahn SR, Agnelli G, Goldhaber S, Raskob GE and Comerota AJ; American College of Chest Physicians: Antithrombotic therapy for venous thromboembolic disease: American College of Chest Physicians evidence-based clinical practice guidelines (8th Edition). Chest 133 (6 Suppl): 454S-545S, 2008.

4. Decousus H, Leizorovicz A, Parent F, et al: A clinical trial of vena caval filters in the prevention of pulmonary embolism in patients with proximal deep-vein thrombosis. Prevention du Risque d'Embolie Pulmonaire par Interruption Cave Study Group. N Engl J Med 338: 409-415, 1998.

5. Young T, Tang $\mathrm{H}$ and Hughes R: Vena caval filters for the prevention of pulmonary embolism. Cochrane Database Syst Rev 2: CD006212, 2010.

6. Athanasoulis CA, Kaufman JA, Halpern EF, Waltman AC, Geller SC and Fan CM: Inferior vena caval filters: review of a 26-year single-center clinical experience. Radiology 216: 54-66, 2000.

7. Luke HA: Angiography of the aorta and great vessels; Seldinger's technique of arterial catheterization. Clin Rep 8: 31-54.

8. Taber SW and Bergamini TM: Long-term venous access: indications and choice of site and catheter. Semin Vasc Surg 10: 130-134, 1997.

9. Tadavarthy SM, Castaneda-Zuniga W, Salomonowitz E, et al: Kimray-Greenfield vena cava filter: percutaneous introduction. Radiology 151: 525-526, 1984.

10. McCowan TC, Ferris EJ, Carver DK and Harshfield DL: Use of external jugular vein as a route for percutaneous inferior vena caval filter placement. Radiology 176: 527-530, 1990.

11. Théry C, Asseman P, Becquart J, Bauchart JJ, Jabinet JL and Marache P: Temporary caval filter allowing diagnosis and fibrinolytic therapy in patients suspect of massive pulmonary embolism. Arch Mal Coeur Vaiss 84: 525-530, 1991 (In French).

12. Adelman S: An emergency intravenous route for the pediatric patient. JACEP 5: 596-598, 1976.

13. Beitzke A, Gamillscheg A, Nagel B and Koestenberger M: Femoral vein access by contrast-guided puncture in cardiac catheterization in patients under one year of age. Pediatr Cardiol 30: 768-770, 2009.

14. Baekgaard N, Broholm R, Just S, Jørgensen M and Jensen LP: Long-term results using catheter-directed thrombolysis in 103 lower limbs with acute iliofemoral venous thrombosis. Eur J Vasc Endovasc Surg 39: 112-117, 2010. 
15. Sillesen H, Just S, Jørgensen M and Baekgaard N: Catheter directed thrombolysis for treatment of ilio-femoral deep venous thrombosis is durable, preserves venous valve function and may prevent chronic venous insufficiency. Eur J Vasc Endovasc Surg 30: 556-562, 2005.

16. Grassi CJ, Swan TL, Cardella JF, et al: Quality improvement guidelines for percutaneous permanent inferior vena cava filter placement for the prevention of pulmonary embolism. SCVIR Standards of Practice Committee. J Vasc Interv Radiol 12: 137-141, 2001.

17. Blebea J, Wilson R, Waybill P, et al: Deep venous thrombosis after percutaneous insertion of vena caval filters. J Vasc Surg 30 821-828, 1999.

18. Li Z, Lu W, Zhao Y, Yu Y, Yang D and Liu Q: The stent treatment of vena iliaca through great saphenous vein in Cockett syndrome. Chin J Surg 48: 1896-1897, 2010.

19. Su H-B, Gu J-P, Lou W-S, et al: Catheter-directed thrombolysis for acute iliofemorai deep vein thrombosis via the ipsilateral great saphenous vein approach: a comparative clinical study. Chin J Radiol 45: 1185-1189, 2011.

20. Li X, Liu W and Zhang C: The analysis of 7 cases: thrombolysis catheter treatment of cohort superficial vein through great saphenous vein in patients with acute legs deep venous thrombosis. Chin J Trauma Disabil Med 20: 76-77, 2012.

21. Ye B, Xia L, Xie Y and Deng X: The intracavitary therapy of Cockett syndrome thtough left great saphenous vein. J Gannan Med Univ 26: 384-385, 2006

22. Chen G, Gu J, Su H, et al: Application of venography of lower extremity via a percutaneous great saphenous vein access. J Clin Radiol 27: 514-517, 2008.

23. Zhang Y, Zhang Q, Lou R, Meng L and Wang X: Filter insertion treatment of small incision through the saphenous vein of inferior vena cava: 30 cases of clinical observation. Chin J Gen Surg 17: 610-610, 2002

24. Zhang Y, Zhang Q, Lou Y, et al: Clinical appficafion of inferior vena cava filter placement through great saphenous vein. Zhejiang Med J 28: 264-266,320, 2006.
25. Spivack DE, Kelly P, Gaughan JP, van Bemmelen PS: Mapping of superficial extremity veins: normal diameters and trends in a vascular patient-population. Ultrasound Med Biol 38: 190-194, 2012.

26. Oliva VL, Szatmari F, Giroux MF, Flemming BK, Cohen SA and Soulez G: The Jonas study: evaluation of the retrievability of the Cordis OptEase inferior vena cava filter. J Vasc Interv Radiol 16: 1439-1445, 2005.

27. Rosenthal D, Swischuk JL, Cohen SA and Wellons ED: OptEase retrievable inferior vena cava filter: initial multicenter experience. Vascular 13: 286-289, 2005.

28. Ziegler JW, Dietrich GJ, Cohen SA, Sterling K, Duncan J and Samotowka M: PROOF trial: protection from pulmonary embolism with the OptEase filter. J Vasc Interv Radiol 19: $1165-1170,2008$

29. Onat L, Ganiyusufoglu AK, Mutlu A, et al: OptEase and TrapEase vena cava filters: a single-center experience in 258 patients. Cardiovasc Intervent Radiol 32: 992-997, 2009.

30. Kalva SP, Marentis TC, Yeddula K, Somarouthu B, Wicky S and Stecker MS: Long-term safety and effectiveness of the "OptEase" vena cava filter. Cardiovasc Intervent Radiol 34: 331-337, 2011.

31. Millward SF, Grassi CJ, Kinney TB, et al: Reporting standards for inferior vena caval filter placement and patient follow-up: supplement for temporary and retrievable/optional filters. J Vasc Interv Radiol 16: 441-443, 2005.

32. Imberti D, Ageno W and Carpenedo M: Retrievable vena cava filters: a review. Curr Opin Hematol 13: 351-356, 2006.

33. Nicholson W, Nicholson WJ, Tolerico P, et al: Prevalence of fracture and fragment embolization of Bard retrievable vena cava filters and clinical implications including cardiac perforation and tamponade. Arch Intern Med 170: 1827-1831, 2010.

34. Redberg RF: Medical devices and the FDA approval process: balancing safety and innovation; comment on "prevalence of fracture and fragment embolization of bard retrievable vena cava filters and clinical implications including cardiac perforation and tamponade". Arch Intern Med 170: 1831-1833, 2010. 